\title{
The potential of near infrared spectroscopy (NIRS) to measure the chemical composition of aquaculture solid waste
}

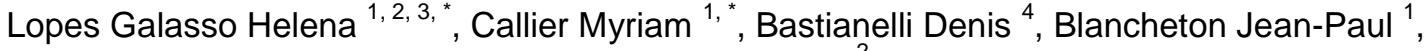 \\ Aliaume Catherine ${ }^{2}$
}

${ }^{1}$ Ifremer, UMR MARBEC (IRD - Ifremer - Univ. Montpellier - CNRS), Chemin de Maguelone, F-34250 Palavas les Flots, France

2 Université de Montpellier, UMR MARBEC (IRD - Ifremer - Univ. Montpellier - CNRS), Place Eugène Bataillon, F-34095 Montpellier, France

${ }^{3}$ CAPES Foundation, Ministry of Education of Brazil, Brasília DF 70040-020, Brazil

${ }^{4}$ CIRAD, UMR SELMET, Systèmes d'élevage méditerranéens et tropicaux, F-34398 Montpellier, France

* Corresponding authors : Helena Lopes Galasso, email address : Helena.Lopes.Galasso@partenaireexterieur.ifremer.fr ; Myriam Callier, email address : $\underline{\text { myriam.callier@ifremer.fr }}$

\begin{abstract}
:
In aquaculture, it is extremely important to determine the composition of fish farm waste to evaluate its potential impacts and to improve its reuse. Near-infra red spectroscopy (NIRS), an alternative to standard chemical analytical techniques, is a quick non-invasive method to assess physical and chemical composition, reducing the cost of routine analysis. We developed NIRS calibration models for organic matter (OM), total organic carbon (TOC), total organic nitrogen (TON), the carbon/nitrogen ratio $(\mathrm{C} / \mathrm{N})$, total phosphorus (TP) and the lipid content of marine fish particulate waste. To obtain a wide range of compositions of fish waste, decomposition time, feed loss, and inter-specific variations were taken into account. The NIRS calibration models were built using three sub-datasets: in Scenario 1) the calibration was species-specific, including only seabass waste (SeabassWaste), in Scenario 2), the calibration included data from two other species (MultiSpeciesWaste) and in Scenario 3), the general calibration included all data as well as simulation of extreme feed loss (up to 50\%) (Faeces\&Feed). All calibrations performed using either dried or wet samples gave equations with high coefficients of determination (R2) and reasonably low standard error of cross validation (SECV) values for all parameters tested, except for TP due the high proportion of mineral P.
\end{abstract}

Highlights 
- This is the first study demonstrating the potential of the NIRS methodology to predict the organic composition of fish farm waste. NIRS calibration can be successfully used to predict the organic composition of Dicentrarchus labrax faeces. NIRS method provides rapid and precise information on fish faeces composition in terms of OM, TOC, TON, the $\mathrm{C} / \mathrm{N}$ ratio and lipid content.

Keywords : Near infrared spectroscopy, Fish farm waste, Faeces, Dicentrarchus labrax, Chemical composition 


\section{Introduction}

Intensive aquaculture has developed rapidly and one of the main concerns regarding the potential environmental impact of this industry is how to manage farm effluents. The release of fish farm waste (e.g. uneaten feed and faeces) into the environment may have a potential impact on ecosystems through the accumulation of organic matter and eutrophication (see the review in Hargrave, 2005; Mente et al., 2006). Modification of the composition of the sediment under fish cages may alter habitat, change the composition of benthic communities, reduce biodiversity and cause possible disease out-breaks (Ferreira et al., 2013). Negative impacts are generally observed in low current-velocity areas or in case of overfeeding (Pearson and Black, 2001).

Fish retain only a fraction of the feed nutrients they ingest, i.e. carbon $(\mathrm{C})$, nitrogen $(\mathrm{N})$ and phosphorous $(\mathrm{P})$. In salmon and trout farms, up to $80 \%$ of $\mathrm{C}, 76 \%$ of $\mathrm{N}$ and $82 \%$ of $\mathrm{P}$ of the 
feed introduced into a system may be lost to the environment (Hall, 1992; Holby and Hall, 1991). In salmon farms, Wang et al. (2013) estimated that $C, N$, and $P$ waste represented $70 \%$ of the total feed input of $\mathrm{C}$ (of which $48 \%$ was respired by fish), $62 \%$ of the total feed input of $\mathrm{N}$, and $70 \%$ of the total feed input of P. In a study on seabass farming, Roque d'Orbcastel and Blancheton (2006) estimated that the proportion of nutrients assimilated by seabass was 15$20 \%$ for N, $50 \%$ for $\mathrm{P}$ and $22 \%$ for $\mathrm{C}$. They evaluated that $60-86 \%$ of $\mathrm{N}$ and $15 \%$ of $\mathrm{P}$ was in lost as dissolved nutrients (mainly in the form of ammoniacal $\mathrm{N}$ and orthophosphate), $6-15 \%$ was lost through faecal production as particulate organic nitrogen (PON), 20\% as particulate phosphorous (TP) and 25\% as particulate organic carbon (POC).

Solid waste in farm effluents is composed of faeces and uneaten feed pellets. Faeces composition depends mainly on the species (physiology and feeding behaviour) and the composition of the feed (ingredient digestibility). Farm waste composition also depends on the proportion of uneaten feed pellets. It is assumed that $5-10 \%$ of total feed input is lost as uneaten feed (Bureau et al., 2003; Cromey et al., 2002; Pérez et al., 2002; Reid et al., 2009). The type of production system could also influence effluent composition. Faeces and uneaten feed rapidly break down into fine and more soluble particles. In land-based systems for instance, decomposition and mineralization occurring in the tank and pipes, may change the composition of the waste before its release into the environment (Timmons and Ebeling, 2010).

It is important to determine the composition of solid waste to evaluate its potential impacts and reuses (Davies, 2000; McGhie et al., 2000). Usual chemical laboratory analyses apply standard methods that may be very costly and time consuming. Near infrared reflectance spectroscopy (NIRS), an alternative to standard chemical techniques, is a rapid analytical method to assess physical and chemical composition. NIRS consists in measuring the 
absorbance at wavelength in the near infrared spectral region $(800-2500 \mathrm{~nm})$, sometimes extended to the visible region (400-800nm). Near infrared light is absorbed at wavelengths corresponding to chemical bonds within an organic molecules, thus providing qualitative and quantitative information (Blanco and Villarroya, 2002). The analytical information contained in an NIR spectrum can be extracted using various multivariate analysis techniques such as PLS regression. Analytical variables are related to sample properties, thus making it possible to group samples with similar characteristics (Manley, 2014). The calibration model relates the spectral properties of a sample to reference (laboratory) measurements. After validation, the models can be used to predict the analytical values corresponding to spectra from new samples.

Once calibrated, NIRS allows fast characterization of organic compounds since it requires no - or only moderate - processing of the samples, and portable spectrometers can be used to perform field measurements (Blanco and Villarroya, 2002). Moreover, compared to traditional laboratory analyses, NIRS is a non-destructive method that preserves the sample's wholeness, enables the measurement of a large number of parameters using a single sample, and reduces the cost of routine analysis (Blanco and Villarroya, 2002). In aquaculture, NIRS is currently used to measure the chemical composition of oysters (Brown, 2011; Guévélou and Allen, 2016), to check flesh and body quality in fishes (reviewed by Cozzolino et al., 2002; Folkestad et al., 2008), to characterize ovarian follicular atresia (Servid et al., 2011), to trace fish geographical origins (Liu et al., 2015) and to assess protein and energy digestibility in rainbow trout (Glencross et al., 2015). Beyond these applications, NIRS could also be used in studies on integrated farming systems where it is essential to determine the quality of waste produced by one species that becomes the main food source for other species with different trophic levels. It might also be of interest in the fields of environmental impact assessment, 
nutrition (e.g. digestibility experiments) or in the self-control of effluent composition in a good farm management practices plan.

The aim of this study was to evaluate the potential of NIRS to measure the composition of farmed seabass waste. Specifically, we developed NIRS calibration models for organic matter (OM), total organic carbon (TOC), total organic nitrogen (TON), total phosphorus (TP) and the lipid content of particulate matter. To obtain calibration models covering a wide range of situations, it is essential to include as much variability as possible. In this study two factors affecting seabass waste composition were considered: faeces decomposition and the proportion of uneaten feed in the waste. Moreover, faeces from two other species (Liza ramada and Sarpa salpa) were also analysed to add an inter-specific variation to the NIRS calibrations. Three calibrations with different scenarios were built for the spectrum using dry samples. A species-specific calibration was computed with only seabass faeces (SeabassWaste) including samples with all decomposition times and feed addition variations up to $10 \%$ (realistic conditions), a second inter-specific calibration included additional data from two other species, mullet and salema (MultiSpeciesWaste), and a third, general calibration (Faeces\&Feed) also included feed additions up to 50\% (extreme food loss). For more rapid characterization of fish faeces, additional calibrations were computed with spectra using wet samples (WetSeabassWaste), which cuts out the drying process.

\section{Materials and methods}

\subsection{Farm system}

The faeces samples were taken from an experimental recirculating aquaculture system located at the Ifremer station (Palavas-les-Flots, French Mediterranean coast). Fish were reared in 2 and $5 \mathrm{~m}^{3}$ tanks equipped with a sea water treatment system including a mechanical filter, a 
biofilter, a UV disinfection unit and a decantation tank. Seabass (Dicentrarchus labrax) were fed ad libitum with commercial pellets containing $43 \%$ crude protein, $20 \%$ crude fat and $8 \%$ ash (NEO grower extra marin sinking 5 - Le Gouessant). Mullet (Liza ramada) and salema (Sarpa salpa) were raised in similar tanks but fed with feed containing $39.5 \%$ crude protein, $0.5 \%$ crude fat and $15.4 \%$ ash (special feed with Ulva sp.).

\subsection{Fish waste sampling and preparation}

The faeces of the seabass, mullet and salema were collected from settling tanks directly connected to the bottom of the fish rearing tanks. The fish were fed with self-feeders which were stopped $2 \mathrm{~h}$ before sample collection. To avoid collecting uneaten feed pellets in the samples, the settling tanks were emptied and cleaned before the beginning of the harvest. After 16h, samples were collected by opening a valve at the bottom of the settling tank or by siphoning the water and then transferring it into decantation tanks $(15 \mathrm{~L})$ for $1 \mathrm{~h}$ to concentrate the solids (e.g. faeces and associated bacteria). The decanted matter was collected by gravity. At the laboratory, $50 \mathrm{~mL}$ of decanted material was centrifuged (5000 rpm for 5 minutes). The liquid phase was discarded and the solid phase with a moisture content of $70-80 \%$ was homogenised by mixing. Wet sub-samples weighing $35 \mathrm{~g}$ (weighed with a precision balance, Precisa 401AM-FR) were placed in plastic Petri dishes and frozen at $-22^{\circ} \mathrm{C}$ until the NIRS analysis. After the NIRS analysis using the wet matter (see section 2.5), the samples were dried in an oven at $55^{\circ} \mathrm{C}$ for $24 \mathrm{~h}$ and ground (Retsch grinder with a $1 \mathrm{~mm}$ mesh) for later dry NIRS reading.

\subsection{Creating variability in the fish waste samples}

To calibrate the NIRS over a wide range of seabass waste compositions, a set of samples $(\mathrm{n}=38)$ was left to biodegrade for $16 \mathrm{~h}, 24 \mathrm{~h}, 48 \mathrm{~h}$ and $72 \mathrm{~h}$ in the decantation tanks. Another set of fish samples $(n=24)$ was mixed with various percentages of uneaten feed, ranging from a 
realistic percentage, i.e. $5,10 \%$, to percentages representing extreme loss, i.e. 20, 30, 40 and $50 \%$ (\% of faeces WW). In addition, data concerning mullet and salema faeces were also introduced into the database $(n=23)$. The sampling, storage and spectrum measurement methods were the same as those used for the other samples.

\subsection{Chemical analyses}

Organic matter $(\mathrm{OM})$ was determined by loss on ignition (ashing at $550^{\circ} \mathrm{C}$ for $4 \mathrm{~h}$ ). Lipid content was determined using the Soxlhet extraction method with petroleum ether after acid hydrolysis (ISO6492, 1999). Total organic nitrogen (TON) was determined using the Kjeldahl procedure. Total organic carbon (TOC) and total organic nitrogen were determined by high temperature combustion at $1000^{\circ} \mathrm{C}$ with a INTEGRA CN Sercon ${ }^{\circledR}$ mass spectrometer (Raimbault et al., 2008) on aliquots of 1-2 mg of decarbonated dry matter using $50 \mu \mathrm{L}$ of $\mathrm{H}_{2} \mathrm{SO}_{4}(0.5 \mathrm{~N})$. The $\mathrm{C} / \mathrm{N}$ ratio was calculated by dividing the values of TOC by those of TON obtained with the same method. Total phosphorus (TP) was determined on $1 \mathrm{ml}$ aliquots obtained by wet oxidation $\left(120^{\circ} \mathrm{C}\right)$ in the presence of potassium persulfate (Menzel and Corwin, 1965) by colorimetric assay of the phosphate formed. All constituents were expressed on a dry weight (DW) basis. Dry weight was measured after oven-drying at $103^{\circ} \mathrm{C}$ for $24 \mathrm{~h}$.

\subsection{Near infrared spectroscopy}

For each sample, two different NIR spectra were collected:

- a first NIR spectrum was recorded on wet thawed samples in reflectance mode from 350 to $2500 \mathrm{~nm}$ with a Labspec Pro spectrometer (ASD, Boulder, CO, USA) and a High Intensity Contact Probe (spot diameter $10 \mathrm{~mm}$ ). Each sample was mixed and scanned 10 times and the spectra were averaged. 
- the second spectrum was recorded on dried material. The dried and ground samples were scanned in reflectance mode on a monochromator $(1100-2500 \mathrm{~nm}$ with $2 \mathrm{~nm}$ step) NIRSystem 5000 spectrometer (FOSS, Laurel, MD, USA). Samples were packed in round sample cups with quartz glass windows (diameter $36 \mathrm{~mm}$ ). The spectra were acquired in duplicate (with two different cup fillings) and averaged. Fig. shows typical absorbance spectra collected on wet (A) and dry (B) fish faeces samples.

To optimize the performance of the calibration models, several mathematical spectral pretreatments were tested (Naes et al., 2002), i.e. derivation order (no derivative, first and second derivative), smoothing and derivation gap (on 5, 10, 15 or 20 data points), as well as spectral standardization processes (standard normal variate transformation, detrending, multiplicative scatter correction). The pre-treatments selected for dry sample calibration was first-order derivation smoothed with a gap of 5 data points after detrending and normalization. For the wet samples, the pre-treatment that fitted best was multiplicative scatter correction, secondorder derivation smoothed with a gap of 20 data points. The calibration models were obtained by PLS (partial least squares) regression (Wold et al., 2013) using the WINISI software MPLS procedure (WINISI 4, Infrasoft Intl., Port Matilda, PA, USA).

\subsection{NIRS calibration scenarios}

Three calibrations were built with different scenarios for the spectrum using dry samples. One calibration was species-specific with only seabass waste (SeabassWaste, $\mathrm{n}=46$ ) including samples with all decantation times and with feed addition variations up to $10 \%$ (realistic conditions). To add another variation to the NIRS calibrations, a second inter-specific calibration was built with additional data from other two species, mullet and salema (MultiSpeciesWaste, $\mathrm{n}=69$ ). Finally, a third, general calibration (Faeces\&Feed, $\mathrm{n}=85$ ) also included feed additions up to $50 \%$ (extreme food loss). The three scenarios were created to 
increase the variability of the fish waste samples to add robustness to the NIRS calibration model. For more rapid characterization of fish waste, additional calibrations were computed with spectra using wet samples, which cut out the drying process (WetSeabassWaste, $\mathrm{n}=46$ ).

\subsection{Statistical analyses}

Non-parametric one-way ANOVA (Kruskal-Wallis test) $(\mathrm{P}>0.05)$ was used to test the effect of decantation time, feed addition and species on the chemical composition of fish waste.

The performances of the PLS calibration models were evaluated using the standard error of calibration (SEC) and the coefficient of determination of the regression between the predicted and measured parameters $\left(\mathrm{R}^{2}\right)$ as described by Naes et al. (2002). Due to the limited number of samples available, cross-validation was used to validate the models. Cross-validation was performed on four groups by sequentially calibrating three groups and validating the fourth group (25\% left-out, 4 times). Validation performance was expressed by the standard error of cross-validation (SECV), the coefficient of determination for cross-validation $\left(\mathrm{R}^{2}\right)$ and the residual predictive deviation (RPD), defined as the ratio of the standard deviation of the original data (SD) to the SECV (Williams, 2001). Calibration outliers were removed from the calibration set based on examination of the prediction residuals in 2 outlier elimination passes ( $\mathrm{T}$ tests with $\mathrm{T}>2.5$ ). The database was also tested for spectral outliers, but the elimination threshold was voluntarily high (Mahalanobis distance $\mathrm{H}>5$ ) to keep variability in the databases even with less typical samples, thereby increasing the robustness of the models.

\section{Results}

\subsection{Creation of variability: decomposition time, feed addition and species}


The average chemical compositions of fish waste by species, feed addition $(0,5,10,20,30$, 40 and 50\%) and decomposition time (16, 24, 48 and 72h) are presented in Table 1. Chemical content of the waste ranged from $44.1-76.5 \%$ for OM, $1.7-5.2 \%$ for TON, $11.4-50.8 \%$ for TOC, 8.8-25.5 for the $\mathrm{C} / \mathrm{N}$ ratio, 1.0-3.2 for TP and 1.7-11.8\% for lipids.

The creation of variability between the samples based on decomposition times, feed losses and different species was efficient, as illustrated by the significant differences between the samples with different treatments (p-values resulting from the non-parametric one-way ANOVA,Kruskal-Wallis test). Decomposition times had a significant effect on OM ( $\mathrm{P}=0.0012)$, TON $(\mathrm{P}=0.0003)$, TOC $(\mathrm{P}=0.0117)$, the $\mathrm{C} / \mathrm{N}$ ratio $(\mathrm{P}=0.0013)$ and lipid content $(\mathrm{P}=0.0090)$. Only for TP there was no significant difference $(\mathrm{P}>0.05)$. As expected, feed addition had a significant effect on the composition of the waste. The higher the amount of uneaten feed added to the faeces samples, the higher the OM $(\mathrm{P}=0.0002)$, TON $(\mathrm{P}=0.0002)$, TOC ( $\mathrm{P}=0.0003)$ and lipid content $(\mathrm{P}=0.0001)$ were found. The $\mathrm{C} / \mathrm{N}$ ratio $(\mathrm{P}=0.0075)$, however, was not significantly affected by changes in added feed. In terms of nitrogen and lipid content, the gradual addition of feed to the faeces samples showed that the quality of fish particulate waste was highly sensitive to feed losses. Mullet and salema faeces had the same composition, differing significantly from that of seabass in terms of $\mathrm{OM}(\mathrm{P}=0.0008)$, TOC $(\mathrm{P}=0.0006)$, the $\mathrm{C} / \mathrm{N}$ ratio $(\mathrm{P}=0.0007), \mathrm{TP}(\mathrm{P}=0.0280)$, lipid content $(\mathrm{P}=0.0001)$, but not in terms of TON $(\mathrm{P}=0.5208)$.

\subsection{Calibration models}

The fitted regressions between the NIRS spectrum using dried samples and laboratory values originating from calibration models for $\mathrm{OM}$, TON, TOC, TP, the $\mathrm{C} / \mathrm{N}$ ratio and lipids are shown in $\mathrm{P}=\mathrm{p}$-value of the Kruskal-Wallis test (not significant $\mathrm{P}>0.05$ ). Separate models were done for each factor. 
Table . Due to different variability (SD) in the three calibration datasets, they must be compared using SEC or SECV values rather than $\mathrm{R}^{2}$ values because the latter are strongly linked to SD.

Calibration accuracy of most parameters was good, with particularly good results being obtained for OM, TON and Lipids. The precision of the TOC and the $\mathrm{C} / \mathrm{N}$ ratio predictions was acceptable. In contrast, the calibrations for $\mathrm{TP}$ were not efficient with extremely low $\mathrm{R}^{2}$ values (0.05 to 0.23$)$ being obtained. The SEC values were close to laboratory standards for $\mathrm{OM}(\mathrm{SEC}=0.32$ to $0.62 \%$ ), $\mathrm{TON}$ (SEC=0.04 to $0.07 \%$ ) and lipids ( $\mathrm{SEC}=0.15$ to $0.20 \%$ ).

Cross-validation gave SECV values higher than SEC values by $27 \%$ on average (4 to $75 \%$ according to parameters and datasets), obviously due to the limited number of samples in the datasets. However, the SECV values were still low for most parameters and indicated the good prediction ability of the models, as illustrated by RPD values above 3 for most parameters except in the Seabass Waste dataset where there was far less variability.

Specific seabass calibrations (SeabassWaste) were equally or more precise than in the two other scenarios for most parameters except TOC. The difference was particularly high for OM with a SEC value nearly twice as high in Faeces\&Feed dataset compared to SeabassWaste. However, the ratio between SECV and SEC, which is an indication of the stability of the models, was higher in the SeabassWaste dataset, obviously due to the lower number of calibration samples.

\subsection{NIRS $x$ Measured Regressions}

There was a strong linear relationship between the measured laboratory values and the values predicted by NIRS within the calibration sets. Cross-validation equations were successfully developed for seabass faeces composition in terms of OM, TOC, TON, the $\mathrm{C} / \mathrm{N}$ ratio and lipid content, as demonstrated by the regression relationship between measured and predicted 
values (Fig. 2). MPLS regression of the NIRS spectrum and laboratory values produced high quality calibration models for all parameters, except for TP content.

\subsection{NIRS prediction using wet samples}

The calibration results for the WetSeabassWaste samples are presented in Table 3. The precision of the NIRS predictions was relatively good when considering the spectrum acquisition conditions: the SECV values were close to those of corresponding calibrations using dried samples and even better for TOC. The only parameter for which precision was highly degraded was $\mathrm{OM}(\mathrm{SEC}=1.17 \%$ vs. $0.32 \%$ in dried samples $)$.

In general, the SECV values of the calibration equations developed with spectra collected using wet samples was much higher than the SEC values, suggesting the models are relatively sensitive to variations in the calibration datasets and their capacity for extrapolation at this stage is minimal.

\section{Discussion}

\subsection{Calibration models}

The use of NIRS in ecological and aquaculture research is dependent on the development of robust calibration models allowing the assessment of the composition of a large range of waste with a good accuracy. This study confirms the potential of the NIRS methodology to predict the organic composition of seabass - and other fish - waste in terms of organic matter, total organic nitrogen, total organic carbon, the $\mathrm{C} / \mathrm{N}$ ratio and lipid content. The variability created in terms of species, decomposition time and feed addition reinforced the robustness of this calibration model. To date, no other NIRS calibration has been established to predict the composition of fish faeces. 
The SeabassWaste calibration showed good correlations between NIRS predictions and laboratory values (OM, TOC, TON, the $\mathrm{C} / \mathrm{N}$ ratio and lipids). When variability was increased with two other species (MultiSpeciesWaste), the $\mathrm{R}^{2}$ and SECV values became more accurate for all measured parameters. Similar results were obtained in the calibration with all samples and all factors (Faeces\&Feed) creating variability, such as decomposition time, feed addition and different species.

Calibration using wet samples was less accurate than with dry samples. However, the calibration model (WetSeabassWaste) using wet samples demonstrated that it is possible to skip the drying process while maintaining good accuracy for all parameters except for TP. The SECV value indicates that the wet sample spectrum could be interesting and allow much faster solid waste characterization in terms of OM, TOC, TON and lipids (Table 33, session 3.4).

\subsection{Dicentrarchus labrax faeces characterization}

Fish faeces composition is an important indication of nutritional factors and provides information on how they can be potentially reused. Variations in decomposition time and feed loss proportions resulted in changes in fish waste composition. In this study, the composition of the mixture of Dicentrarchus labrax faeces and feed, excluding the samples with extremely high feed content, was on average $2.3 \pm 0.2 \% \mathrm{TON}, 28.6 \pm 5.7 \% \mathrm{TOC}$ and $2.1 \pm 0.5 \% \mathrm{TP}$. The values found in this study are within the characterization range of previous studies (Roque d'Orbcastel and Blancheton, 2006) with 0.6 to $2.6 \%$ for TP and 0.5 to $2.4 \%$ for TON, but the values were slightly higher than those obtained for TOC, i.e. 22 to $24.7 \%$ by Wang et al. (2013). Wang et al. (2013) found that the faeces composition of Salmo salar raised in cages in Norway was similar for $\mathrm{C}$ (31.2 to $45.8 \%), \mathrm{N}$ (2.2 to $3.7 \%)$ and $\mathrm{P}$ (1.4 to $3.0 \%)$, with the exception of lipid content (6.4 to $8.9 \%)$ that was a little more concentrated in their study. 


\subsection{Predictions on changes in composition}

As stated earlier, there is considerable loss of nutrients in fish farming, related both to the animals' digestion and to direct loss of uneaten feed. Quantification of this organic matter is important to characterize the residue and to determine how it should be treated or its potential uses. It is important to know the changes over time of the $\mathrm{C}, \mathrm{N}$ and $\mathrm{P}$ contents to follow the mineralization process. The efficiency of NIRS predicting organic matter content in seabass faeces samples was excellent in all calibration models with $\mathrm{R}^{2}$ always above 0.94 and SECV values varying between 0.53 and $2.00 \%$ with spectra using both dry and wet samples. These results of predicted $\mathrm{OM}$ content obtained with fish faeces are more accurate than predictions of this parameter in other studies on rabbit faeces $\left(\mathrm{R}^{2}=0.83\right.$ and $\left.\mathrm{SECV}=0.86 \%\right)$ (NúñezSánchez et al. 2012) or on feed digestibility with pig faeces $\left(\mathrm{R}^{2}=0.80\right.$ and $\left.\mathrm{SECV}=0.87 \%\right)$ (Bastianelli et al. 2014). They are similar to those obtained by Althaus et al. (2013) on dairy cow faeces $\left(\mathrm{R}^{2}=0.95\right.$ and $\left.\mathrm{SECV}=0.72 \%\right)$.

In terms of TON, the calibration $\mathrm{R}^{2}$ values ranged from 0.95 to 0.99 , which is more precise than the TON predictions of Bastianelli et al. (2014) $\left(\mathrm{R}^{2}=0.88\right.$ and $\left.\mathrm{SECV}=0.09 \%\right)$. Other NIRS calibrations with animal waste also gave coefficient values as high as 0.97 in terms of TON content (Althaus et al., 2013). In this same study, we found the NIRS TOC calibration to be less accurate when compared to total carbon predictions $\left(\mathrm{R}^{2}=0.97\right.$ and $\left.\mathrm{SECV}=0.7 \%\right)$. Although, the TOC predictions in seagrass composition by Bain et al. (2013) were less accurate $\left(\mathrm{R}^{2}=0.67\right.$ and $\left.\mathrm{SECV}=1.18 \%\right)$.

Phosphorus is a relevant compound released in fish faeces that settles in culture tanks. It has also been suggested that it may be a useful indicator of fish farm waste loading (Holmer and Heilskov, 2008). For TP predictions, none of the NIRS calibrations gave satisfactory $\mathrm{R}^{2}(0.11$, 0.54 and 0.53$)$, SECV $(0.36,0.25$ and $0.23 \%)$ and RPD (0.91, 1.35 and 1.38) values. NIRS 
prediction for mineral and inorganic compounds is not very efficient as these compounds do not absorb infrared light (Clark et al., 1986). The phosphorus content of fish waste comes mainly from undigested fish feed in the form of apatite, $\mathrm{Ca}_{5}\left(\mathrm{PO}_{4}\right)_{3}$ and originates from two by-products, fish scales and bones (Neori et al., 2007). This observation confirms the low quality of NIRS predictions for total phosphorus in samples with high inorganic content. However, a study using the NIRS method showed it was possible to characterize both apatite and non-apatite phosphate groups based on decomposition and absorption of infrared bands (Bouhaouss et al., 2001). Nonetheless, further studies are required to determine the relative proportions of mineral phosphate in fish faeces (Stenberg et al., 2010).

Another parameter used to qualify available organic matter is the $\mathrm{C} / \mathrm{N}$ ratio. Each organism has an optimal $\mathrm{C} / \mathrm{N}$ ratio for its development. Consequently, changes in this ratio can modify the bacterial community, directly influencing the decomposition and mineralization of organic matter. The range of the $\mathrm{C} / \mathrm{N}$ ratio range was wide and the ratio varied especially with the different origins of fish species (10.3 to 23.0). All calibrations based on dry matter analyses (SeabassWaste, MultiSpeciesWaste and Faeces\&Feed) provided accurate calibration in terms of the $\mathrm{C} / \mathrm{N}$ ratio. However, the calibrations based on wet samples gave less accurate results with lower $\mathrm{R}^{2}$, SECV and RPD values.

The differences in lipid content due to feed addition were very significant for the different species with different feeding behaviours. The NIRS calibration equations using lipid content of dry or wet samples provided much more accurate results than those obtained in a digestibility study with rainbow trout (Oncorhynchus mykiss) $\left(\mathrm{R}^{2}=0.88\right)$ performed by Glencross et al., (2015), and these were also better than a lipids content prediction in egg yolks $\left(\mathrm{R}^{2}=0.85\right)$ (Dalle Zotte et al., 2006). Seabass usually digest the fatty acids in their diet efficiently, but the part lost in their faeces may be a possible source of lipids for other cocultures in integrated multi trophic systems (Brown et al., 2011). 


\section{Conclusion}

This study showed that NIRS calibration can be successfully used to predict the organic composition of Dicentrarchus labrax faeces and that the NIRS method provides rapid and precise information on fish faeces composition in terms of OM, TOC, TON, the $\mathrm{C} / \mathrm{N}$ ratio and lipid content. The results demonstrated a strong relationship between the NIRS predictions and the values measured by usual laboratory analyses. To improve the efficiency of this method and to further improve NIRS predictions of organic compounds in marine fish waste, further samples need to be included in the calibration process and validations with external data are recommended. This work also confirmed the difficulty to measure TP in fish faeces due to a high proportion of the mineral form of $\mathrm{P}$ and an absence of correlation with other compounds. Expanding the calibration database with other fish species decreased the precision of the calibrations for some parameters, but obviously increased their robustness. The development of a much more complete database could allow the composition of samples collected in various conditions to be predicted and would therefore be a very useful tool. In a broader context, the use of NIRS could be extended to the study of feed digestibility, the quality of fish faeces and its potential as a food resource for co-cultivated species, and for environmental impact studies.

\section{Acknowledgements}

The authors would like to thank Philippe Cacot, Laurent Bonnal, and Elodie Baby for their great help. This work was supported by the "Science Without Boarders" program of the Brazilian government (CAPES PhD Scholarship No. 13.773-13-5). These results were obtained within the framework of the ERA-Net COFASP project (IMTA-Effect project) with funding from The French National Research Agency (ANR) and Ifremer UMR MARBEC (IMTA-Model project, "Politique de site"). 


\section{References}

Althaus, B., Papke, G., Sundrum, A., 2013. Technical note: Use of near infrared reflectance spectroscopy to assess nitrogen and carbon fractions in dairy cow feces. Anim. Feed Sci. Technol. 185, 53-59. doi:10.1016/j.anifeedsci.2013.07.003

Bain, K.F., Vergés, A., Poore, A.G.B., 2013. Using near infra red reflectance spectroscopy (NIRS) to quantify tissue composition in the seagrass Posidonia australis. Aquat. Bot. 111, 66-70. doi:10.1016/j.aquabot.2013.05.012

Bastianelli, D., Bonnal, L., Jaguelin-Peyraud, Y., Noblet, J., 2014. Predicting feed digestibility from NIRS analysis of pig faeces. Animal 2, 1-6. doi:10.1017/S1751731114003097

Blanco, M., Villarroya, I., 2002. NIR spectroscopy: a rapid-response analytical tool. TrAC Trends Anal. Chem. 21, 240-250. doi:10.1016/S0165-9936(02)00404-1

Bouhaouss, A., Bensaoud, A., Moussaouiti, M. El, Ferhat, M., 2001. Analyse fine de l'apatite analogue aux biomateriaux par la spectroscopie infrarouge. Phys. Chem. News 1, 125129.

Brown, M.R., 2011. Rapid compositional analysis of oysters using visible-near infrared reflectance spectroscopy.

Aquaculture

317,

233-239. doi:10.1016/j.aquaculture.2011.04.017

Brown, N., Eddy, S., Plaud, S., 2011. Utilization of waste from a marine recirculating fish culture system as a feed source for the polychaete worm, Nereis virens. Aquaculture 322-323, 177-183. doi:10.1016/j.aquaculture.2011.09.017

Bureau, D.P., Gunther, S.J., Cho, C.Y., 2003. Chemical composition and preliminary theoretical estimates of waste outputs of rainbow trout reared in commercial cage culture operations in Ontario. N. Am. J. Aquac. 65, 33-38. doi:10.1577/15488454(2003)065<0033:CCAPTE > 2.0.CO;2 
Clark, D.H., Mayland, H.F., Lamb, R.C., 1986. Mineral analysis of forages with near Infrared Reflectance Spectroscopy. Agron. J. 79, 485-490.

Cozzolino, D., Murray, I., Scaife, J.R., 2002. Near infrared reflectance spectroscopy in the prediction of chemical characteristics of minced raw fish. Aquac. Nutr. 8, 1-6. doi:10.1046/j.1365-2095.2002.00176.x

Cromey, C.J., Nickell, T.D., Black, K.D., 2002. DEPOMOD - modelling the deposition and biological effects of waste solids from marine cage farms. Aquaculture 214, 211-239. doi:10.1016/S0044-8486(02)00368-X

Dalle Zotte, A., Berzaghi, P., Jansson, L.M., Andrighetto, I., 2006. The use of near-infrared reflectance spectroscopy (NIRS) in the prediction of chemical composition of freezedried egg yolk and discrimination between different n-3 PUFA feeding sources. Anim. Feed Sci. Technol. 128, 108-121. doi:10.1016/j.anifeedsci.2005.09.009

Davies, I.M., 2000. Waste production by farmed atlantic salmon (Salmo salar) in Scotland. Sustain. Aquac. Dev. 1-6.

Ferreira, J.G., Grant, J., Verner-Jeffreys, D.W., Taylor, N.G.H., 2013. Carrying capacity for aquaculture, Modeling frameworks for determination of, in: Sustainable Food Production. Springer New York, New York, NY, pp. 417-448. doi:10.1007/978-14614-5797-8_904

Folkestad, A., Wold, J.P., Rørrvik, K.A., Tschudi, J., Haugholt, K.H., Kolstad, K., Mørkøre, T., 2008. Rapid and non-invasive measurements of fat and pigment concentrations in live and slaughtered Atlantic salmon (Salmo salar L.). Aquaculture 280, 129-135. doi:10.1016/j.aquaculture.2008.04.037

Glencross, B., Bourne, N., Hawkins, W., Karopoulos, M., Evans, D., Rutherford, N., Mccafferty, P., Dods, K., Burridge, P., Veitch, C., Sipsas, S., Buirchell, B., Sweetingham, M., 2015. Using Near Infrared Reflectance Spectroscopy (NIRS) to 
predict the protein and energy digestibility of lupin kernel meals when fed to rainbow trout, Oncorhynchus mykiss. Aquac. Nutr. 21, 54-62. doi:10.1111/anu.12137

Guévélou, E., Allen, S.K., 2016. Use of Near Infrared Reflectance Spectroscopy (NIRS) for the rapid compositional analysis of di-, tri-, and tetraploid eastern oysters (Crassostrea virginica). Aquaculture 459, 203-209. doi:10.1016/j.aquaculture.2016.03.022

Hall, O.J., 1992. Chemical flux and mass balances in a marine fish cage farm. IV. Nitrogen. Mar. Ecol. Prog. Ser. 89, 81-91.

Hargrave, B., 2005. Environmental effects of marine finfish aquaculture. The handbook of environmental chemistry, Vol 5. ed. Water pollution, Part M. Springer, Berlin.

Holby, O., Hall, P.O.J., 1991. Chemical fluxes and mass balances in a marine fish cage farm. II. Phosphorus. Mar. Ecol. Prog. Ser. 70, 263-272.

Holmer, M., Heilskov, A.C., 2008. Distribution and bioturbation effects of the tropical alpheid shrimp Alpheus macellarius in sediments impacted by milkfish farming. Estuar. Coast. Shelf Sci. 76, 657-667. doi:10.1016/j.ecss.2007.07.033

ISO6492, 1999. Aliment des animaux. Détermination de la teneur en matière grasse.

Liu, Y., Ma, D. hong, Wang, X. chang, Liu, L. ping, Fan, Y. xia, Cao, J. xuan, 2015. Prediction of chemical composition and geographical origin traceability of Chinese export tilapia fillets products by near infrared reflectance spectroscopy. LWT - Food Sci. Technol. 60, 1214-1218. doi:10.1016/j.lwt.2014.09.009

Manley, M., 2014. Near-infrared spectroscopy and hyperspectral imaging: non-destructive analysis of biological materials. Chem. Soc. Rev. 43, 8200-8214. doi:10.1039/c4cs00062e

McGhie, T.K., Crawford, C.M., Mitchell, I.M., O’Brien, D., 2000. The degradation of fishcage waste in sediments during fallowing. Aquaculture 187, 351-366. doi:10.1016/S0044-8486(00)00317-3 
Mente, E., Pierce, G.J., Santos, M.B., Neofitou, C., 2006. Effect of feed and feeding in the culture of salmonids on the marine aquatic environment: A synthesis for European aquaculture. Aquac. Int. 14, 499-522. doi:10.1007/s10499-006-9051-4

Menzel, D.W., Corwin, N., 1965. The measurement of total phosphorus in seawater based on the liberation of organically - bound fractions by persulphate oxidation. Limnol. Ocean. 280-282. doi:10.4319/1o.1965.10.2.0280

Naes, T., Isaksson, T., Davies, T., 2002. Validation, in: A user-friendly guide to multivariate calibration and classification. NIR Publication, Chichester, UK, p. 344.

Neori, A., Krom, M.D., Rijn, J. Van, 2007. Biogeochemical processes in intensive zeroeffluent marine fish culture with recirculating aerobic and anaerobic biofilters. J. Exp. Mar. Bio. Ecol. 349, 235-247. doi:10.1016/j.jembe.2007.05.023

Núñez-Sánchez, N., Martínez Marín, A.L., Hernández, M.P., Carrion, D., Castro, G.G., Pérez Alba, L.M., 2012. Faecal near infrared spectroscopy (NIRS) as a tool to asses rabbit's feed digestibility. Livest. Sci. 150, 386-390. doi:10.1016/j.livsci.2012.07.030

Pearson, T.H., Black, K.D., 2001. The environmental impact of marine fish cage culture, in: Black, K.D. (Ed.), Environmental Impacts of Aquaculture. Sheffield Academic Press, Sheffield, pp. 1-31.

Pérez, O.M., Telfer, T.C., Beveridge, M.C.M., Ross, L.G., 2002. Geographical Information Systems (GIS) as a simple tool to aid modelling of particulate waste distribution at marine fish cage sites. Estuar. Coast. Shelf Sci. 54, 761-768. doi:10.1006/ecss.2001.0870

Raimbault, P., Garcia, N., Cerutti, F., 2008. Distribution of inorganic and organic nutrients in the South Pacific Ocean - evidence for long-term accumulation of organic matter in nitrogen-depleted waters. Biogeosciences 5, 281-298. doi:10.5194/bgd-4-3041-2007 
Reid, G.K., Liutkus, M., Robinson, S.M.C., Chopin, T.R., Blair, T., Lander, T., Mullen, J., Page, F., Moccia, R.D., 2009. A review of the biophysical properties of salmonid faeces: Implications for aquaculture waste dispersal models and integrated multitrophic aquaculture. Aquac. Res. 40, 257-273. doi:10.1111/j.1365-2109.2008.02065.x

Roque d'Orbcastel, E., Blancheton, J.P., 2006. The wastes from marine fish production systems: characterization, minimization, treatment and valorization, in: World Aquaculture. pp. 28-35.

Servid, S.A., Talbott, M.J., Eenennaam, J.P. Van, Doroshov, S.I., Struffenegger, P., Webb, M.A.H., Cavinato, A.G., 2011. Rapid noninvasive characterization of ovarian follicular atresia in cultured white sturgeon (Acipenser transmontanus) by near infrared spectroscopy.

Aquaculture

315 , 290-297. doi:10.1016/j.aquaculture.2010.11.052

Stenberg, B., Viscarra Rossel, R.A., Mouazen, A.M., Wetterlind, J., 2010. Chapter Five Visible and Near Infrared Spectroscopy in soil science, in: Advances in Agronomy. pp. 163-215. doi:10.1016/S0065-2113(10)07005-7

Timmons, M.B., Ebeling, J.M., 2010. Recirculating Aquaculture, 2nd ed. Cayuga Aqua Ventures, United States.

Wang, X., Andresen, K., Handå, A., Jensen, B., Reitan, K.I., Olsen, Y., 2013. Chemical composition and release rate of waste discharge from an Atlantic salmon farm with an evaluation of IMTA feasibility. Aquac. Environ. Interact. 4, 147-162. doi:10.3354/aei00079

Williams, P.C., 2001. Implementation of Near-Infrared Technology, in: Williams, P., Norris, K. (Eds.), Near-Infrared technology in the Agricultural and Food Industry. American Association of Cereal Chemists, St. Paul, MN, USA, pp. 145-169. 
Wold, S., Ruhe, A., Wold, H., Dunn III, W.J., 2013. The collinearity problem in linear regression. The partial least squares (PLS) approach to generalized inverses. SIAM J. Sci. Stat. Comput. 5, 735-743. 
Table 1. Characterization of fish waste. Effects of a) decomposition time (16, 24, 48 and 72h), b) feed addition $(0,5,10,20,30,40$ and 50\%) in seabass faeces and c) inter-specific variability, Number of samples (n), mean \pm SD (\% of dry weight) of organic matter (OM), total organic nitrogen (TON), total organic carbon (TOC), carbon/nitrogen ratio $(\mathrm{C} / \mathrm{N})$, total phosphorus (TP) and lipids.

\begin{tabular}{cccccccc}
\hline & n & OM & TON & TOC & C/N & TP & Lipids \\
\hline a) Decomposition & & & & & & & \\
16h & 6 & $54.6 \pm 6.2$ & $2.1 \pm 0.3$ & $22.4 \pm 6.7$ & $12.8 \pm 1.9$ & $2.2 \pm 0.6$ & $4.2 \pm 0.6$ \\
$24 \mathrm{~h}$ & 10 & $62.2 \pm 5.7$ & $2.4 \pm 0.1$ & $27.6 \pm 6.1$ & $13.3 \pm 2.3$ & $1.9 \pm 0.5$ & $4.9 \pm 0.4$ \\
$48 \mathrm{~h}$ & 10 & $62.0 \pm 5.8$ & $2.2 \pm 0.1$ & $29.7 \pm 5.2$ & $16.2 \pm 2.8$ & $2.0 \pm 0.5$ & $4.5 \pm 0.1$ \\
$72 \mathrm{~h}$ & 12 & $61.1 \pm 5.4$ & $2.1 \pm 0.1$ & $30.1 \pm 4.8$ & $15.5 \pm 2.0$ & $2.2 \pm 0.4$ & $4.8 \pm 0.3$ \\
P value & & 0.0012 & 0.0003 & 0.0117 & 0.0013 & 0.6141 & 0.0090
\end{tabular}

b) Feed lost

$\begin{array}{lccccccc}0 \% & 38 & 60.6 \pm 6.1 & 2.2 \pm 0.2 & 28.1 \pm 6.0 & 14.7 \pm 2.6 & 2.0 \pm 0.5 & 4.6 \pm 0.4 \\ 5 \% & 4 & 59.7 \pm 3.3 & 2.4 \pm 0.1 & 31.3 \pm 3.5 & 13.1 \pm 0.8 & 2.1 \pm 0.5 & 5.2 \pm 0.3 \\ 10 \% & 4 & 61.4 \pm 2.4 & 2.7 \pm 0.1 & 30.4 \pm 4.8 & 12.0 \pm 1.2 & 2.1 \pm 0.4 & 6.1 \pm 0.2 \\ 20 \% & 4 & 64.5 \pm 0.8 & 3.2 \pm 0.2 & 35.8 \pm 1.5 & 10.8 \pm 0.8 & 2.0 \pm 0.1 & 7.7 \pm 0.2 \\ 30 \% & 4 & 67.8 \pm 0.8 & 3.7 \pm 0.4 & 37.5 \pm 1.9 & 10.5 \pm 1.3 & 1.9 \pm 0.1 & 8.8 \pm 0.8 \\ 40 \% & 4 & 70.4 \pm 2.1 & 4.1 \pm 0.5 & 43.0 \pm 5.4 & 9.6 \pm 0.7 & 1.8 \pm 0.2 & 9.1 \pm 1.2 \\ 50 \% & 4 & 73.2 \pm 3.3 & 4.5 \pm 0.7 & 42.4 \pm 5.7 & 9.6 \pm 0.6 & 2.0 \pm 0.6 & 10.1 \pm 1.5 \\ \text { P value } & & 0.0002 & 0.0002 & 0.0003 & 0.0075 & 0.6808 & 0.0001\end{array}$

c) Species
D. labrax
$62 \quad 62.8 \pm 6.4$
$2.7 \pm 0.8$
$31.5 \pm 7.3$
$13.2 \pm 2.9 \quad 2.0 \pm 0.4$
$5.9 \pm 2.0$
L. ramada
$\begin{array}{ll}18 & 74.4 \pm 0.8\end{array}$
$2.1 \pm 0.2 \quad 37.9 \pm 3.8$
$21.1 \pm 1.9 \quad 1.7 \pm 0.2$
$1.9 \pm 0.1$
S. salpa
Pvalue
$\begin{array}{ll}5 & 72.1 \pm 3.6\end{array}$
$2.3 \pm 0.3$
$34.4 \pm 5.7$
$18.1 \pm 3.8 \quad 1.8 \pm 0.2$
$2.2 \pm 0.3$
0.0008
0.0006
$0.0007 \quad 0.0280$
0.0001

\section{Total}

$\begin{array}{llllll}85 & 65.8 \pm 7.4 & 2.5 \pm 0.7 & 33.0 \pm 7.1 & 15.2 \pm 4.3 & 1.9 \pm 0.4\end{array}$

$4.8 \pm 2.4$

$\mathrm{P}=\mathrm{p}$-value of the Kruskal-Wallis test (not significant $\mathrm{P}>0.05$ ). Separate models were done for each factor. 
Table 2. NIRS calibration models (SeabassWaste, MultiSpeciesWaste and Faeces\&Feed) with a spectrum of dry samples.

\begin{tabular}{lccccccc} 
Seabass Waste $(\mathbf{n = 4 6})$ & & & & & & \\
\hline Parameter & n & Mean & SD & SEC & $\mathbf{R}^{2}$ & SECV & RPD \\
\hline OM & 42 & 61.19 & 4.80 & 0.32 & 1.00 & 0.53 & 8.98 \\
TON & 42 & 2.27 & 0.22 & 0.04 & 0.96 & 0.07 & 3.36 \\
TOC & 42 & 29.24 & 4.67 & 2.25 & 0.77 & 2.80 & 1.67 \\
C/N & 43 & 14.11 & 2.40 & 0.78 & 0.90 & 0.83 & 2.87 \\
TP & 41 & 1.99 & 0.40 & 0.39 & 0.05 & 0.43 & 0.94 \\
Lipids & 44 & 4.83 & 0.55 & 0.15 & 0.93 & 0.21 & 2.67 \\
\hline
\end{tabular}

MultiSpecies Waste $(\mathrm{n}=69)$

\begin{tabular}{lccccccc}
\hline Parameter & n & Mean & SD & SEC & R $^{2}$ & SECV & RPD \\
\hline OM & 65 & 65.15 & 7.70 & 0.50 & 1.00 & 0.70 & 10.94 \\
TON & 62 & 2.21 & 0.23 & 0.05 & 0.95 & 0.07 & 3.31 \\
TOC & 65 & 31.92 & 6.14 & 1.98 & 0.90 & 2.29 & 2.69 \\
C/N & 67 & 16.29 & 3.89 & 0.85 & 0.95 & 0.98 & 3.96 \\
TP & 62 & 1.87 & 0.34 & 0.30 & 0.21 & 0.31 & 1.11 \\
Lipids & 66 & 3.87 & 1.44 & 0.16 & 0.99 & 0.19 & 7.57 \\
\hline
\end{tabular}

Faeces\&Feed $(\mathbf{n}=85)$

\begin{tabular}{lccccccc}
\hline Parameter & $\mathbf{n}$ & Mean & SD & SEC & $\mathbf{R}^{\mathbf{2}}$ & SECV & RPD \\
\hline OM & 83 & 65.90 & 7.17 & 0.62 & 0.99 & 0.81 & 8.86 \\
TON & 81 & 2.49 & 0.69 & 0.07 & 0.99 & 0.09 & 7.51 \\
TOC & 79 & 32.78 & 6.92 & 1.75 & 0.94 & 2.15 & 3.22 \\
C/N & 81 & 15.19 & 4.28 & 0.73 & 0.97 & 0.89 & 4.82 \\
TP & 76 & 1.87 & 0.29 & 0.26 & 0.23 & 0.27 & 1.11 \\
Lipids & 81 & 4.68 & 2.31 & 0.20 & 0.99 & 0.23 & 9.95 \\
\hline
\end{tabular}

Number of samples (n), mean \pm standard deviation (SD) (\% of DW), standard error of calibration (SEC), coefficient of determination of calibration $\left(\mathrm{R}^{2}\right)$, standard error of cross validation (SECV) calculated as the standard deviation divided by the standard error of prediction (RPD). 
Table 3. NIRS calibration models with a spectrum of wet seabass waste samples (WetSeabassWaste).

WetSeabass Waste $(\mathrm{n}=46)$

\begin{tabular}{lccccccc}
\hline Parameter & $\mathbf{n}$ & Mean & SD & SEC & $\mathbf{R}^{2}$ & SECV & RPD \\
\hline OM & 44 & 61.31 & 4.58 & 1.17 & 0.94 & 2.00 & 2.29 \\
TON & 42 & 2.28 & 0.21 & 0.06 & 0.92 & 0.08 & 2.55 \\
TOC & 46 & 28.60 & 5.73 & 1.20 & 0.96 & 2.29 & 2.50 \\
C/N & 41 & 14.36 & 2.18 & 1.09 & 0.75 & 1.41 & 1.55 \\
TP & 44 & 2.04 & 0.46 & 0.30 & 0.56 & 0.40 & 1.14 \\
Lipids & 42 & 4.76 & 0.50 & 0.11 & 0.95 & 0.24 & 2.09 \\
\hline
\end{tabular}

Number of samples in the calibration model (n), mean \pm standard deviation (SD) (\% of DW), standard error of calibration (SEC), coefficient of determination of calibration $\left(\mathrm{R}^{2}\right)$, standard error of cross validation (SECV) calculated as the standard deviation divided by the standard error of prediction (RPD). 
Fig. 1. Mean absorbance spectra collected on wet (A) and dry (B) fish faeces samples by species (D. labrax, L. ramada and S. salpa).

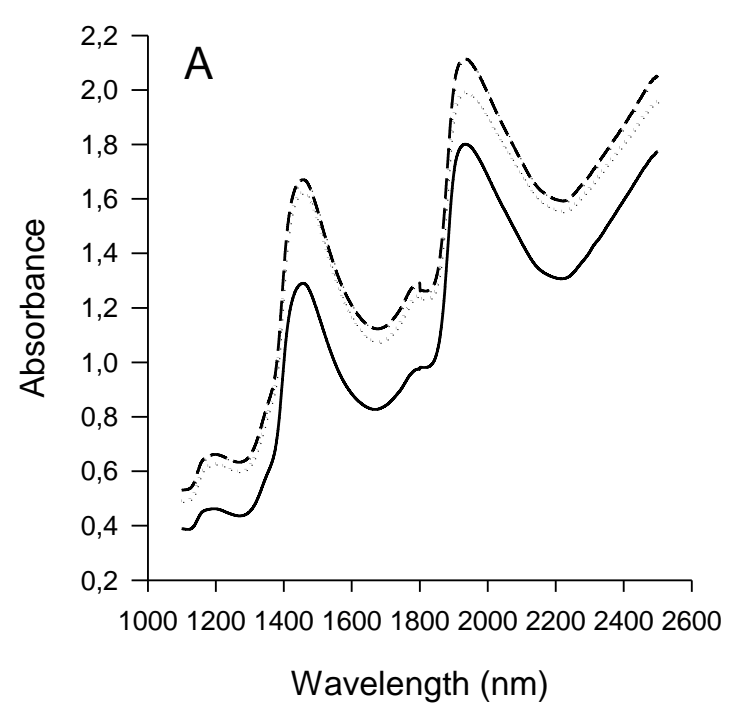

Dicentrarchus labrax

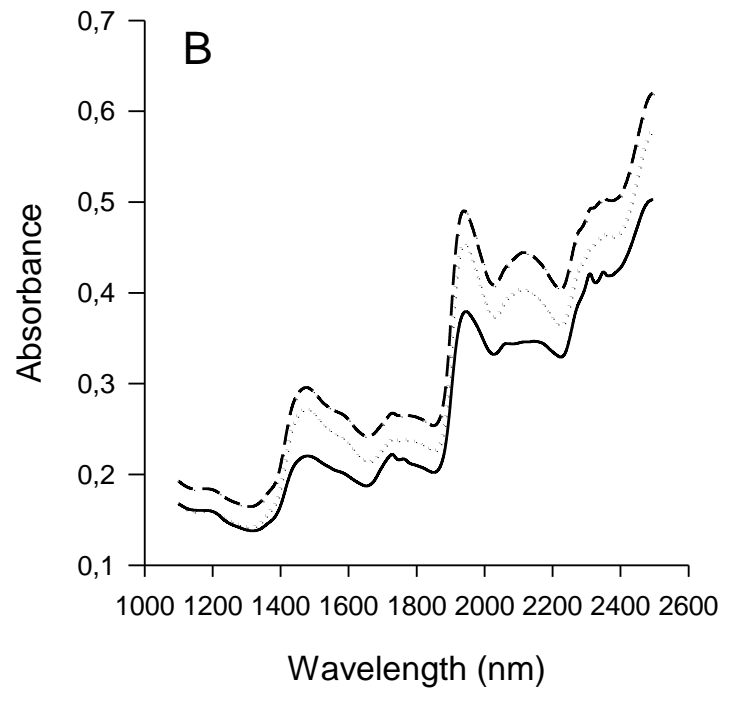

Liza ramada

Sarpa salpa 
Fig. 2. Measured vs. predicted values (\% of dry matter) for organic matter $(\mathrm{OM})$, total organic carbon (TOC), total organic nitrogen $(\mathrm{TON})$, the carbon/nitrogen ratio $(\mathrm{C} / \mathrm{N})$, total phosphorus (TP) and lipid content. Predicted values with a species-specific calibration model, $\mathrm{n}=46$ ( $\mathrm{o}=$ outliers excluded in the calibration process).
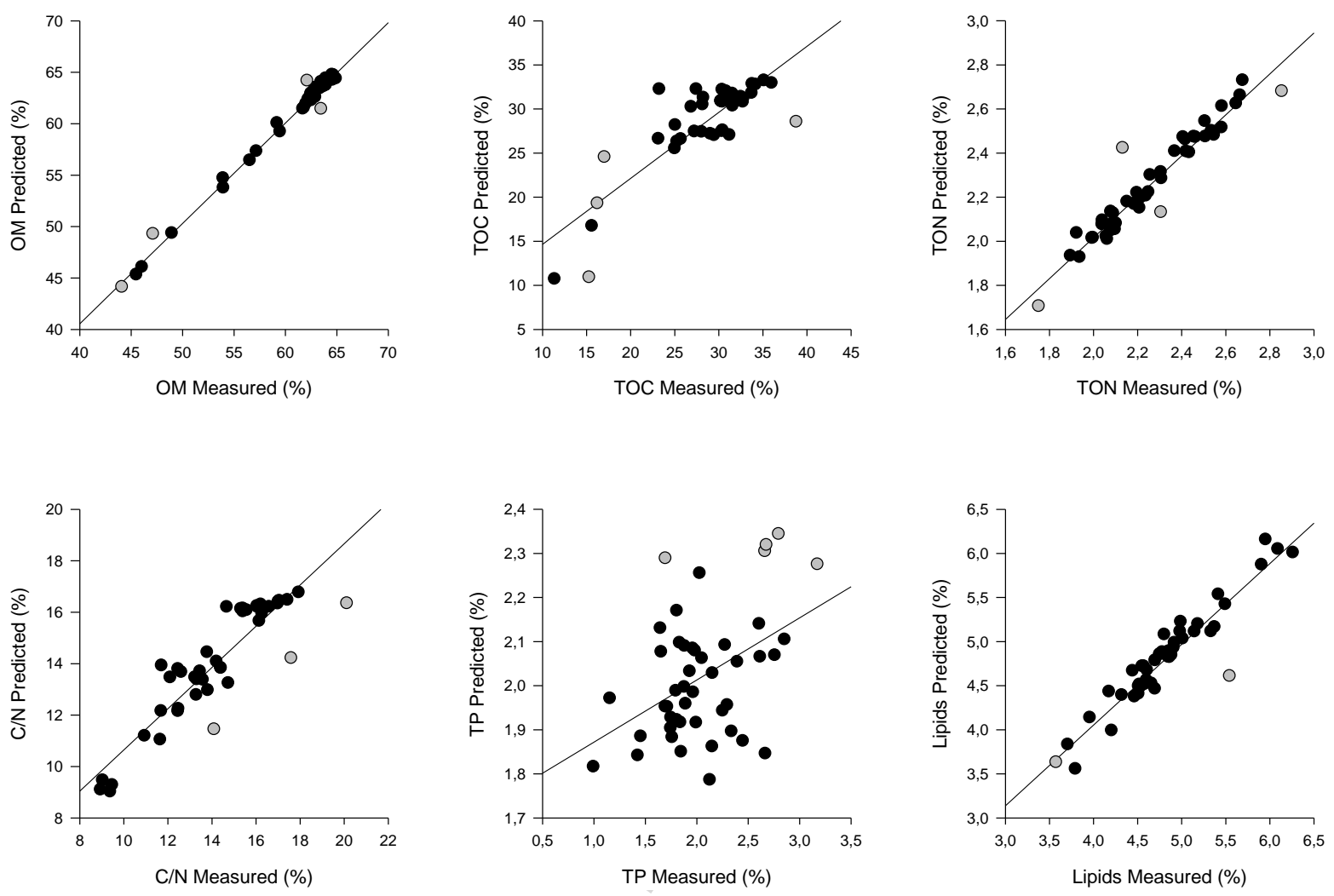